\title{
Types of Vibrato in Contemporary Music and the Possibility of Their Use in Flute Pedagogy
}

\author{
Monika Streitova \\ Music Department, School of Arts of University of Evora, Evora, Portugal \\ Email address: \\ monikastreitova@gmail.com \\ To cite this article: \\ Monika Streitova. Types of Vibrato in Contemporary Music and the Possibility of their use in Flute Pedagogy. American Journal of Art and \\ Design. Vol. 5, No. 4, 2020, pp. 97-102. doi: 10.11648/j.ajad.20200504.13
}

Received: November 5, 2020; Accepted: November 21, 2020; Published: December 4, 2020

\begin{abstract}
This project falls within the area of developing innovative methods in teaching the flute. It focuses on search and application of types of vibrato as contemporary technique of sound production that may contribute to the creative development of classic vibrato and the sonority of the students. The research has been conducted systematically with the aim to deepen the theoretical knowledge and practical skills of the students, learn the types of vibrato and their symbols, and add them to their daily studies. For this purpose, different compositions and excerpts of compositions employing various types of contemporary vibratos have been selected and applied to resolve effectively various problems in sound production and result in a more grounded use of vibrato in the interpretation of contemporary music, as well as music of other historical eras. This objective gains its relevance following the implementation, today unavoidable, of the ancient music movement; this movement decisively transformed the interpretation of baroque and classical music "imposing" on the interpreters, who play on modern instruments, the challenge of finding the sound, wording and expressive resources suitable to the expression and rhetoric of these styles of music. Through auditory analysis and advanced methods of sound analysis was possible to understand and explain the effects of the contemporary vibratos in the modification of the diaphragm support, throat and embouchure, and the respective sound and musical results.
\end{abstract}

Keywords: Flute, Vibrato, Sonority, Experimental Pedagogy, Contemporary Music

\section{Introduction}

Vibrato is a word of Italian origin vibrare, which means to vibrate, to tremble. Vibration is a process closely related to nature. The living being is not static... and "there is no firmness without trembling" [1]. For this reason, the sound vibration is also natural in flute playing. "Vibrato is one of the most widely studied musical features over years. From singing voice to numerous instruments, vibrato shows both very characteristic and also distinctive behavior within instruments."[2].

The ornament in baroque music similar to vibrato, Flattement, "was described in Dutch, English, French and German sources from 1654 to 1847 , including Jacques Hotteterre's Principes de la flûte traversière (1707)" [3]. This effect allowed the slight microtonal oscillation between the notes and was produced with the fingers.

"In the musician's world, sometimes it is not so easy to describe what vibrato means. Of course, it depends mostly on the instrument that the musician plays. If you ask a singer to explain his or her way to do vibrato, it will be totally different from a string player's way. Probably, the flutist's way will be very close to the singer's way. The principle is the same. Nevertheless, all this conception about vibrato has changed over time, and with instrumental changes." [4]. Vibrato flute technique, as we know it today, was first developed in singing. During the bel canto period (an Italian school of singing until the middle of the 19th century), vocal vibrato influenced opera orchestra instrumentalists, and later was also used by flutists. In France, it began to develop in the late 19th and early 20th centuries. In Central Europe, the pioneers of the French flute school only began to spread vibrato in the 1950s. Its use on the flute has already been approached by several pedagogues and flutists.

\section{Vibrato in Contemporary Flute Repertory}

"There are two ways to produce the sound on the flute: straight or with undulations of the air column know as vibrato." 
[5]. Vibrato, in classic flute repertory is a regular pulse of the air column. It consists of opening the throat and pronouncing the vowel "o", while applying light pressure to expel the air. Its correct use produces a relevant sound enrichment in the execution of music from the romantic period.

However, it is also recommended to apply it in lyrical phrases (in classical music, in a more discreet way, and in impressionist or post-romantic music). The use of vibrato requires good taste. It is important that after a historical and aesthetic musical analysis of each work, the possibility of applying vibrato to it is evaluated. To this end, a speed and type of vibrato must be chosen that best suits the character of the work. In contemporary music, classical vibrato is used more sporadically since aesthetics have completely changed. In the context of recent scores, we find it convenient to use it in phrases in pieces that have a post-romantic character or where vibrato is required by the composer. Contemporary music brought to the vibrato world new and different forms.
Contemporary vibratos were for the first time graphically specified by italian composer and bassoonist Bruno Bartolozzi in his book New Sounds for Woodwind (1967).

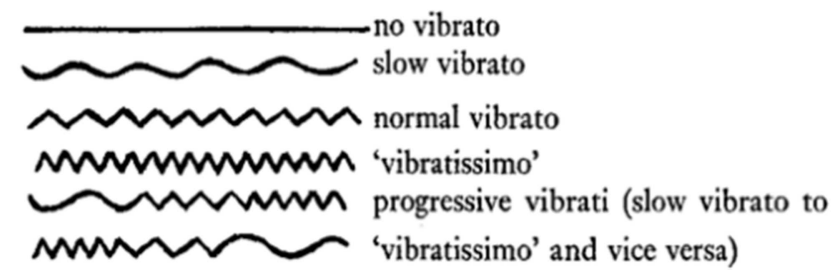

Figure 1. Various types of vibrato defined by B. Bartolozzi. [6].

The french flutist Pierre-Yves Artaud defined concrete symbols to describe all the types and variants presented above. His book Flutes au present (1986) divided the types of vibrato according to speed and amplitude.

\section{$S$ CHEMA}

CHACUN DES TROIS BLEMENTS DU VIBRATO (PRODUCTION, VITBSSE, AMPLITUDE) DOIT FIGURER DANS UNE NOTATION QUI SE VEUT COMPLETE.

\section{DIAGRAM}

BACH OF THE THREE ELEMENTS OF VIBRATO (MEANS OF PRODUCTION, SPEED, AMPLITUDE) MUST FIGURE IN NOTATION, IF THE NOTATION CLAIMS TO BE COMPLETE.

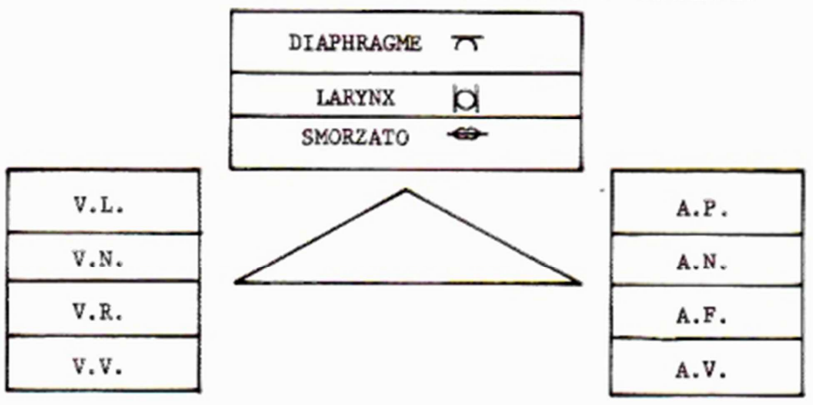

Figure 2. Diagram with symbols of vibratos with their amplitudes. used by P. Y. Artaud in book "Flutes au present”. [7]

These symbols are essential to simplify the composer's work in defining the types of vibratos he wants to include and also

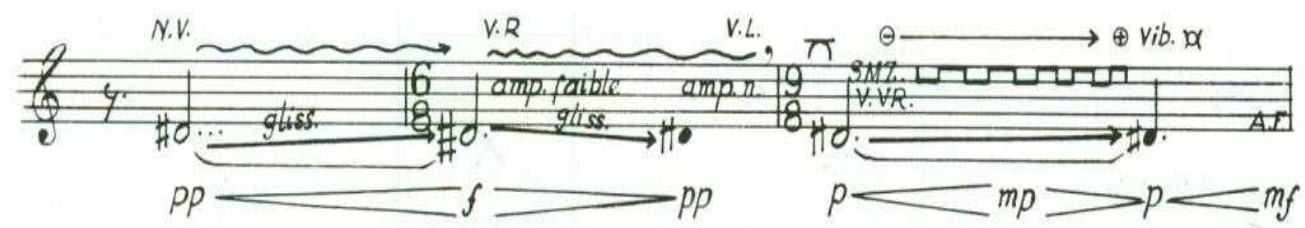

Figure 3. Various types of vibrato. Excerpt of the piece Antiphysis by Hugues Dufourt. [8].

This identification of various types of vibratos gave rise to our project focused on the selection and analysis of vibratos with their amplitudes to find pedagogical application to better control classical vibrato and resolve effectively various problems in sound production of students.

\section{Abbreviations}

During the text of this article, the following abbreviations and symbols will be used: V. L., (vibrato lento) - slow vibrato; V. N., (vibrato normale) - normal vibrato, V. R., (vibrato rapido) - quick vibrato, V. V., (velocita variable) - vibrato with variable speed, N. V., non vibrato - no vibrato, A. P., (amplitudine piccolo) - small amplitude, A. N., (amplitudine normale) - normal amplitude, A. F.(amplitudine forte) strong amplitude, A. V., (amplitudine variable) - amplitude variable, A. P., (amplitudine piccola) - small amplitude.

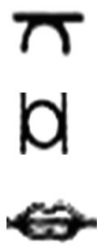

Figure 4. Diaphragm symbol, larynx symbol and lips symbol used by P. Y. Artaud in book "Flutes au present". 


\section{Objectives}

With this research project, we sought to provide students in the first two years of Superior Schools of Music, who already have in their repertoire fundamental pieces of all historical times and who know the instrument in general, a new learning of the flute based on new knowledge that would enable them to find their own sound and at the same time overcome the problems arising from various physical tensions. This process sought to respond to the resolution of the problems identified - technical and aesthetic, in order to find possible solutions through the effective application of contemporary vibratos. One of the important points was regular discussions about the use and execution of vibrato/non vibrato in the interpretation of baroque music and the various types and speeds of vibrato with their own amplitudes in the interpretation of romantic music. The following are some of the difficulties that have arisen:

1. Emission difficulties of classic vibrato (quick vibrato, irregular vibrato, vibrato with the presence of throat noises);

2. Tense throat; Tense lips; Insufficient diaphragmatic support;

3. Limited sound production in the low octave; Tuning problems;

4. Insecurity in the fast passages between the extreme registers;

5. Problems with creating musical phrases;

Difficulty in using different colors and velocities of vibrato to differentiate historical styles.

\section{Metodhology}

The methodology used was based on the experimental empirical method, through the analysis of scores, observation, and listening and critique of sound results. Since this project is experimental and laboratory in nature, the methods were based on the works of G. Landsheere published in book The Experimental Research in Pedagogy. The work with the previously chosen students, was carried out with the using of selected and adapted methods fases suggested by G. Landsheere:

1. To gather the repertoire of pieces where it was possible to apply the types of vibrato as a contemporary flute technique and the set of possible conducts;

2. "Verify the empirical validity of the hierarchical organization of the repertoire through longitudinal studies;

3. Allow students to understand the interactions with us that led to the transformation of behaviors" [9].

4. To catalog the various forms of use of types of vibrato that result in a more conclusive way in the process of development of sound, following them with the theoretical justifications.

\section{Pedagogical Application of vibrato lento with Amplitude forte}

Pedagogical activities with the aim of testing various types of vibrato were divided into individual work and group laboratory work. In the individual work, as an example of the piece covered, we mention the Sonata in A major by César Franck. To achieve a more regular vibrato, we applied a slow vibrato whose impulses actually corresponded to eighth notes. "Slow vibrato is produced with a strong diaphragm movement. It is important, that the air flow remains constant and that the the diaphragm movements do not become jerky and explosive." [10].

The result of this application was not just a more regular vibrato. With the regular impulses produced by the diaphragm, the student also improved the sound quality and the sound became clearer with greater projection.

We proposed to the students that they exclude the little controlled vibrato mode and that in their place they consciously create vibrato always respecting the style and character of the piece.

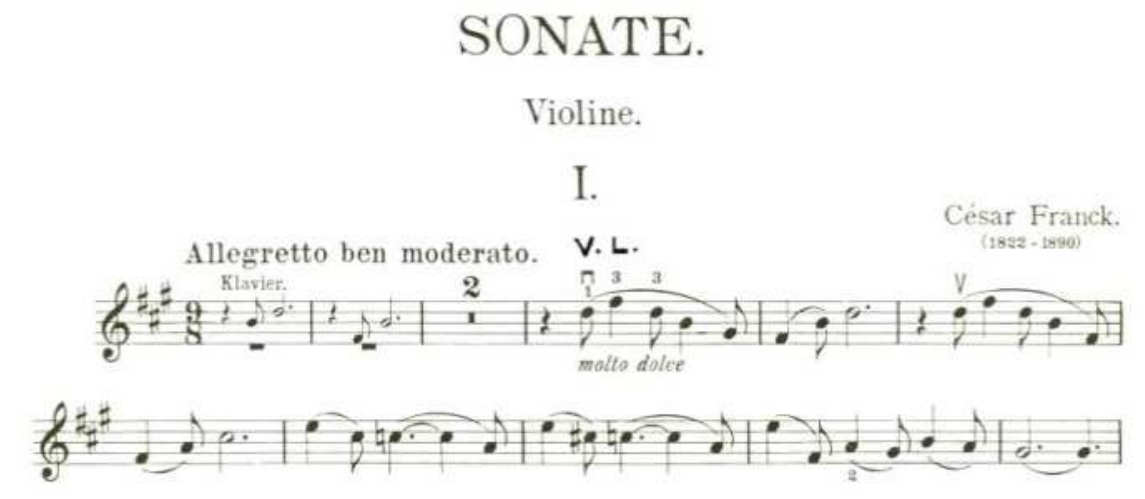

Figure 5. $1^{\circ}$ part of Violin (flute) sonata in A Maior of C. Franck with application of V. L. (Edition Peters). [11]

Audio excerpt $\mathrm{n}^{\circ} 1$ - before the application of V. L.

https://soundcloud.com/monikastreitova/excerpt1-1

Audio excerpt $\mathrm{n}^{\circ} 2$ - after the application of V. L.

https://soundcloud.com/monikastreitova/excerpt2 
The systematization of results included sound analysis. During the laboratory sessions, experimental work and other activities that included the evaluation of results, particular importance was given to the systematic listening of recordings made by the students.

Aurally more conclusive in the group of three students was the application of two types of vibratos: vibrato lento with amplitude forte and slow vibrato with amplitude forte using singing emitted by diaphragm. These proved to have a greater immediate impact on the sound quality of the low register, whose projection on the flute is generally very fragile. We can compare in the images the sound spectrum before, during and after the use of proposed types of vibratos. To obtain the following graphic results, a sound analysis tool, Spectrogram $n^{0} 16$ by Richard Horne was used.

The following are images of spectrograms of application of the vibrato lento technique with amplitude forte in the $\mathrm{C} 4$ tone (2nd - 4th second - natural sound; 4th - 6th second vibrato lento with amplitude forte; 6th - 8th second - natural sound).

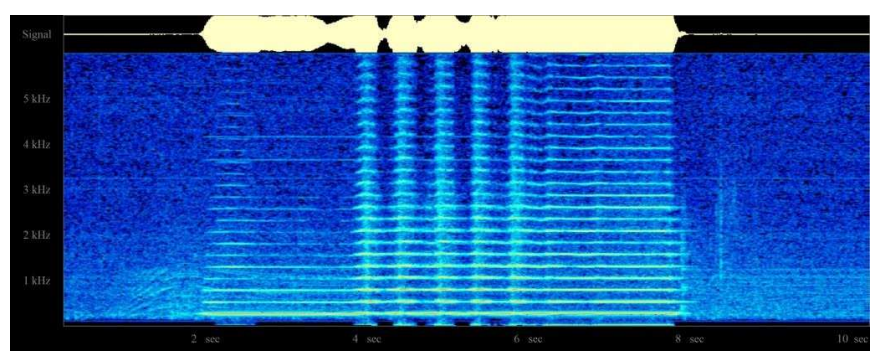

Student A

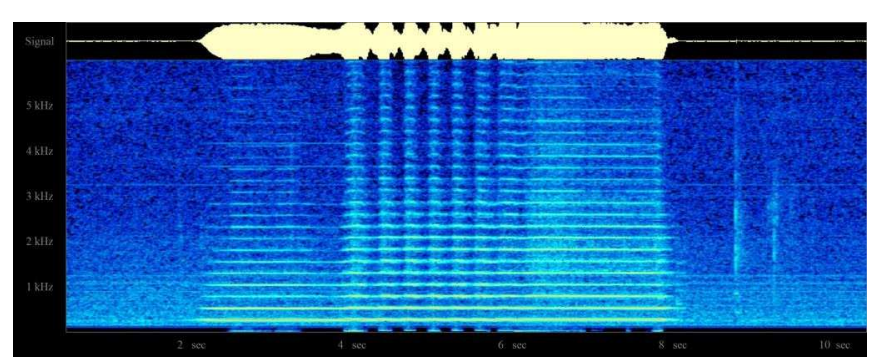

Student B

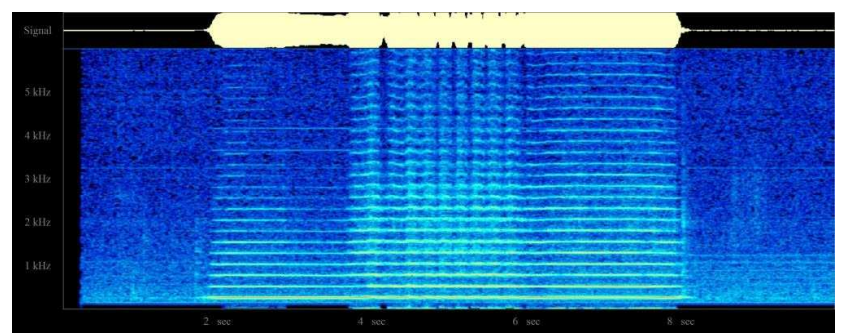

Student C

Figure 6. Comparison of students' results - vibrato lento with amplitude forte. Origin: properly archive.

\subsection{Discussion of Graphical Results}

We tried to prove that the learning and application of various types of vibrato can enrich the sound performance in the various historical musical styles.

As this research project also focuses on the interpretation of classical music, we started by observing the students' playing to see if they performed the vibrato in a natural way without causing tension in the throat. Performing it incorrectly causes tuning and sound quality problems. Only after assessing the vibrato production method did we introduce the application of various forms of vibrato.

\subsection{Interpretation of Graphical Results}

The graphical results of all the students demonstrate significant differences in the sound spectrum when compared to the sound quality, before and after the use of vibrato lento with amplitude forte. The images confirm a truly relevant growth of the high harmonics. This growth resulted from a wider opening of the throat in the production of vibrato, during which a slight pressure was made to expel the air. The sound results were also conclusive from the point of view of the possibilities of applying this technique. The quality of the sound has changed significantly, since the execution of this type of vibrato strengthens and trains the diaphragm and abdominal muscles that are responsible for creating good phrasing. This application was reflected in a greater concentration of sound that provided its greater projection.

"By varying the speed and amplitude of the vibrato, the diaphragm develops a certain flexibility, needed to play staccato for example. Being aware of how vibrato works and what the different options are, will create an extra consciousness of colors in sound." [12].

Contemporary vibrato has many benefits of its application as a mixed technique with singing.

\section{Vibrato as a Mixed Technique and Its Impact in Flute Sound Pedagogy}

With the purpose of testing the influence of vibrato lento with amplitude forte and added singing, we chose the excerpt of the piece by Petra Bachratá, Luminiscence, which was one of pieces selected for this project.

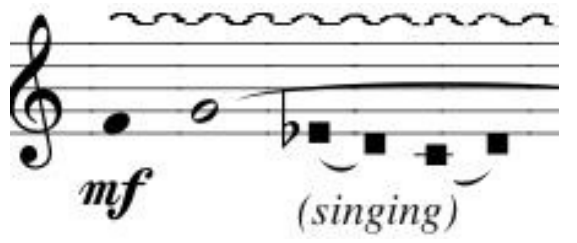

Figure 7. Excerpt of piece "Luminiscence" for solo flute by Petra Bachratá. Origin: Slovak Music Found. [13].

Following are images of spectrograms resulted of the application of the technique of playing with vibrato and singing (excerpt of piece "Luminiscence" by Petra Bachratá). We can observe vibrato enriched with singing at the same time (4th - 6th second). Singing vibrato has a growing spectrum with its origin in the free oscillation of the vocal cords. We can observe vibrato lento ( 2 nd - 4 th second). 


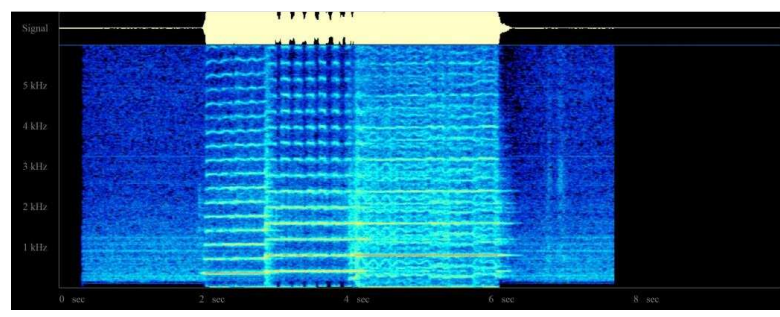

Student A

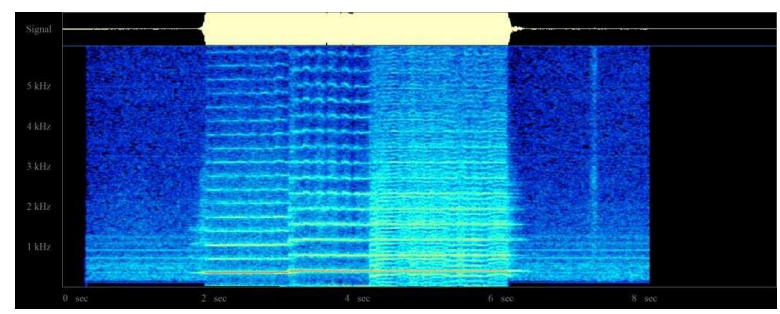

Student B

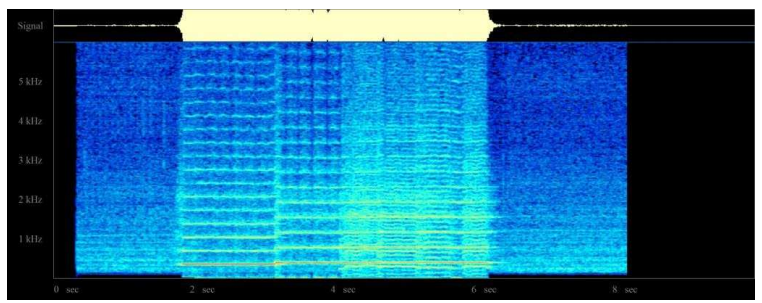

Student C

Figure 8. Comparison of students' results - vibrato lento with amplitude forte and singing. Origin: properly archive.

\subsection{Discussion of Graphical Results}

The purpose of this observation was to demonstrate graphic results of the performance of three components classic playing with slow vibrato, enriched with singing. Between the 4th and 6th seconds we can then observe the change in the spectrum resulting from the use of this technique. In the sound results we can notice a high presence of the whisper that is caused by the oscillation of the air that normally occurs in the production of the simultaneous slow vibrato with singing. The sound of all students demonstrated a high presence of these components. This technique, later applied, revealed an increase in the concentration of the sound that was more focused and more open.

\subsection{Interpretation of Graphical Results}

This combined technique is based on three components present that act at the same time: normal playing, singing and vibrato. The combination of playing and singing at the same time provides an enormous benefit for better performance of the classic sound. Adding the vibrato, whose execution consists of activating the air pulsation in the tone, we obtain, through the presence of the voice, the graphic result that reveals an enormous enrichment of the sound. This was caused by the fact that the throat was even more open and there was free oscillation of the vowel strings. In addition, this process is accompanied by the involvement of the abdominal, lower and upper lumbar muscles, gluteal muscle, intercostal and pectoral muscles, which collaborate in creating support for the diaphragm and which are indispensable for correct breathing. "In singing the tone is produced in the larynx trough vibrations of the vocal folds. These vibrations create the primary laryngeal sound (voice source signal) using subglottic pressure (during expiration) and intrinsic vocal fold muscles and other tissues. This primary laryngeal sound is when modulated by the resonator. The principles of breath support are similar for singing and playing wind instruments. However, in comparison with a singer, the wind instrumentalist needs greater breathing pressure for both the single reed instruments (ie, the clarinet and saxophone) and especially for the double reed instruments (such as oboe and bassoon)". [14]. In the case of sound creation with the flute, the respiratory support resembles the creation of sound in singing and in other wind instruments. However, as previously referred to, being that he lips are not fixed upon the instrument, two-thirds of the air escapes, which results in the necessity of a greater support, as compared to reed instruments.

Creation of sound in singing:

"Air pressure - vocal cords - the first sound - resonance cavities - final sound" [15].

Creation of sound in the flute:

Air pressure - resonance cavities - air oriented for the opening angle of the flute - final sound.

In this way, the air, before entering the cavities, is propelled by the vocal cords, which causes the first sound and whose vibrations initiate the process of widening and preparing the cavities so that they open and reverberate. This moment is paramount when the physical apparatus, which puts the voice into practice, gains the necessary conditions for the production of a higher quality sound. The main benefits of singing include the total relaxing of the throat and putting it to work in a conscious manner with the resonances of the throat cavity and the mouth cavity, in the formation of vowels. The coordination of the neuromuscular mechanisms which give rise to the voice are extremely important, being that it is possible to improve them through training.

The application of this combined technique has the following benefits:

1. More concentrated sound with more projection;

2. More conscious work of the muscles responsible for supporting the diaphragm.

In addition to the previous examples of pedagogical applications, we identified, as very conclusive for the development of the students' sound quality, the following types of vibrato, presented on the Table 1 .

\section{Conclusion}

It has been proven that learning types of vibrato found in

\footnotetext{
${ }^{1}$ Translation by the author. Original text "Tlak vzduchu - hlasivky - prvotní zvuk - resonancní dutiny - výsledný zvuk".
} 
contemporary works can be useful in the development of the domain of classical vibrato production and of flute sonority.

his is because the student, through the production of different speeds and amplitudes, is able to be more conscious of the control of the whole physical apparatus involved in the production of vibrato.

It is necessary that students exclude the constant vibrato mode in all flute repertory of historical styles and that instead they consciously create vibrato respecting the style and character of the piece. For a correct and beneficial application of contemporary vibratos, adequate supervision of students is essential in order to correctly convey the notions and the learning of what can be translated into a correct and adequate sound emission source. This allows the students to achieve a conscious interpretation respecting the style and historical context of the repertory.

Table 1. Possibility of application of selected types of vibrato realized by the diaphragm, larynx and lips. Origin: properly archive.

\begin{tabular}{|c|c|c|c|}
\hline Type of vibrato & Type of amplitude & Technical result & $\begin{array}{l}\text { Aplication in non-conteporary flute } \\
\text { repertory }\end{array}$ \\
\hline $\begin{array}{l}\text { V. L. (vibrato lento) } \\
\text { V. L. (vibrato lento) + singing } \\
\mathbf{T}\end{array}$ & $\begin{array}{l}\text { A. F. (amplitude forte) } \\
\text { A. F. (amplitude forte) } \\
\frac{\pi}{}\end{array}$ & $\begin{array}{l}\text { Applied in the case of difficulties in sound } \\
\text { emission in the low register of flute. } \\
\text { Fortification of the diaphragm and opening of } \\
\text { the throat. }\end{array}$ & $\begin{array}{l}\text { Applied in improving of continuous } \\
\text { phrasing in all historical styles. }\end{array}$ \\
\hline N. V. (non vibrato) & $\mathrm{X}$ & $\begin{array}{l}\text { Applied in the case of the correction of too fast, } \\
\text { very irregular and difficultly controlled vibrato. }\end{array}$ & $\begin{array}{l}\text { Applied in the sonority phrasing } \\
\text { training for interpretation of baroque } \\
\text { music. }\end{array}$ \\
\hline $\begin{array}{l}\text { V. L. (vibrato lento) } \\
\text { Od }\end{array}$ & $\begin{array}{l}\text { A. P. (amplitude picolo) } \\
\text { Dl }\end{array}$ & $\begin{array}{l}\text { Applied in correction of too fast, very irregular } \\
\text { vibrato, with a tendency to cause tension of the } \\
\text { throat, which can cause sounds of their own. }\end{array}$ & $\begin{array}{l}\text { Applied in the interpretation of } \\
\text { romantic repertory. }\end{array}$ \\
\hline$\frac{\text { V. V. (vibrato variable) }}{\pi}$ & $\frac{\text { A. P. (amplitude picolo) }}{\pi}$ & $\begin{array}{l}\text { Applied in the case of correction of vibrato with } \\
\text { limited flexibility }\end{array}$ & $\begin{array}{l}\text { Applied in improving the quality of } \\
\text { sonority in the upper register of flute. }\end{array}$ \\
\hline $\begin{array}{l}\text { V. L. (vibrato lento) } \\
\text { V. V. (vibrato variable) } \\
\infty\end{array}$ & $\begin{array}{l}\text { A. F. (amplitude forte) } \\
\text { A. V. (amplitude variable) } \\
\Leftrightarrow\end{array}$ & $\begin{array}{l}\text { Applied as an auxiliary exercise in preparation } \\
\text { to perform glissando and quarters of tone in } \\
\text { order to achieve a good mastery of the } \\
\text { flexibility of the lips. }\end{array}$ & $\begin{array}{l}\text { Applied in improving the quality of } \\
\text { tuning and the development of the } \\
\text { ability to quickly correct the tuning } \\
\text { with position of embouchure. }\end{array}$ \\
\hline
\end{tabular}

\section{Acknowledgements}

I would like to express my very great appreciation to Prof. Dr. Jorge Salgado Correia and Dr. Jan Svec for their valuable and constructive suggestions during the planning and development of this research work. Their willingness to give their time so generously has been very much appreciated.

I would also like to thank my students who took part in this project for their cooperation and enthusiasm.

In conclusion, I would like to thank my parents for being great examples of excellent teachers who help their students with their whole being.

\section{References}

[1] Halík, T. (2012). There is no firmness without trembling. Nakladatelství Lidové noviny, ISBN: 9788074220241.

[2] Haynes, B. (1997). Flattement. Retrieved 24 October. doi: 10.1093/gmo/9781561592630.article.50911.

[3] Passos, C., Streitova, M. (2020). The use of vibrato in nonhistorical performances. Bulletin of the Transilvania University of Brasov, 10th International Conference, The Science of Music - Excellence in Performance", in press.

[4] Cavdir, D., Picas, R. (2017). Vibrato Analysis Dataset and Derivative Trajectory Parametrization. Retrieved 19 November 2020. https://www.academia.edu/43527295
[5] Woltsenlogel, C. (1995). Método Ilustrado de Flauta. Irmãos Vitale S/A Ind. e Com, pp. 79, São Paulo.

[6] Bartolozzi, B. (1967). New Sounds for Woodwinnd. Oxford University Press, pp. 25, Oxford.

[7] Artaud, P. Y., Geay, G. (1986). Present Day Flutes. Editions Jobert, p. 18, Paris.

[8] Dufourt, H. (1978). Antiphysis, Publisher LEMOINE, Paris, ISBN-13: 979-0230869829.

[9] Landsheere, G. (1982). Pedagogia experimental Edições Dom Quixote, ISBN 9789722004206, pp. 22-24, Lisboa.

[10] Levine, C., Mitropoulos-Bott, Ch. (2002). The Techniques of Flute Playing” Baerenreiter, ISBN 3-7618-1595-6, pp. 32, Kassel.

[11] Franck, C. (1945) Sonata for violin and piano. Edition Peters, ISBN-13: 979-0577080352, ID: EP3742, Lepzig.

[12] Vanoevere, I. (2020). The immediate and long term effects of practicing extended flute techniques on the overall performance qualities in standard flute repertoire. Retrieved 19 November 2020. https://www.academia.edu/42234656/

[13] Bachrata, P. (2005). Luminiscence, Slovensky Hudobny Fond, Bratislava.

[14] Weikert, M., Schlomicher-Their, J. (1999). Laryngeal movements in saxophone playing: Video-endoscopic investigations with saxophone players", Journal of Voice, Vol. 13, No. 2, pp. 265-273.

[15] Švec, J. (2006). Tajemství hlasu. Universita Palackeho v Olomouci, ISBN 80-244-1318-3 pp 17-19, Olomouc. 